\title{
Molecular characterization of Leishmania tropica and Leishmania major from stray dogs and patients in Saudi Arabia
}

Abdullah D Alanazi ( $\sim$ aalanazi@su.edu.sa )

Shaqra University https://orcid.org/0000-0002-4862-7668

Abdulazi S Alouffi S Alouffi

King Abdulaziz City for Science And Technology

Mohamed S Alyousif S Alyousif

King Saud University

Abdulsadah A Rahi

University of Wasit

Magda A Ali

University of Wasit

Fabio A Brayner

Universidade Federal do Pernambucu, Recife

Jairo Alfonso Mendoza-Roldan

Universita degli Studi di Bari

Domenico Otranto

Universita degli Studi di Bari

\section{Research}

Keywords: Leishmania tropica, Leishmania major, Dogs, Patients, kDNA, nPCR, Saudi Arabia

Posted Date: June 22nd, 2020

DOI: https://doi.org/10.21203/rs.2.22961/v3

License: (c) (i) This work is licensed under a Creative Commons Attribution 4.0 International License.

Read Full License 


\section{Abstract}

Background: Leishmania major and Leishmania tropica cause cutaneous leishmaniasis in humans and dogs in several parts of the world, with a large number of cases recorded in the Middle East. However, when occurring in sympatry, the role of each species of Leishmania in the epidemiology of cutaneous leishmaniasis (CL) is not clear.

Methods: To determine the prevalence and to identify the species of Leishmania that infects humans and stray dogs in Riyadh and Al-Qassim (Saudi Arabia), 311 stray dogs and 27 human patients, suspected for Leishmania, were examined for CL by a nested PCR (nPCR).

Results: Nested PCR (nPCR) detected seven patients (25.9\%) positive for cutaneous leishmaniasis. Five patients from Riyadh were infected by L. major and two from Al-Qassim by L. tropica. In addition, five dogs $(1.6 \%)$ were infected by L. tropica .

Conclusions: This is one of the first molecular studies of leishmaniasis from Saudi Arabia. The relationship between the sand fly vectors and the reservoirs of both Leishmania spp. is still scarcely known in this region, and further epidemiological investigations of domestic and wild canids infected with L. major and L. tropica are needed towards a control and prevention of the infection in canine and human populations.

\section{Background}

Leishmaniases are a complex of sand fly transmitted protozoa diseases, listed amongst the neglected tropical diseases affecting millions of people, mainly the world's most vulnerable populations [1]. These diseases are transmitted by phlebotomine sand flies of the genus Phlebotomus in the Old World and Lutzomyia in the New World. Leishmaniases include cutaneous (CL), visceral (VL) and mucocutaneous leishmaniasis (MCL) forms, all of which have been reported in Saudi Arabia [2-4]. Moreover, in that Country CL by Leishmania major has the highest prevalence mainly in Riyadh, Qassim, Al-Madinah, AlHassa, Hail and Asir [5-7] with an estimated number of more than 26,300 cases [2] over the past 10 years (2006-2016). In addition, in Saudi Arabia there are several reports of leishmaniasis by Leishmania infantum (L. infantum), Leishmania major (L. major), and Leishmania tropica (L. tropica) among humans and wild animals [8-12]. In spite of the number of molecular studies available to diagnose and identify Leishmania species worldwide [13-16], there is a lack of information on human CL patients as well as dog populations from endemic areas of Saudi Arabia. El-Beshbishy et al., [17] reported the molecular characterization of CL in patients from Al-Madinah Al-Munawarah province, western Saudi Arabia by internal transcribed spacer 1 (ITS-1) PCR-restriction fragment length polymorphism (RFLP) and kinetoplast DNA (kDNA) PCR established L. major and L. tropica as the causative organisms, with a kDNA PCR sensitivity of $90.7 \%$, whereas ITS-1 PCR had a sensitivity of $70.1 \%$. Rasheed et al., [18] reported the prevalence of Leishmania species among patients with CL in Qassim province, central Saudi Arabia. They recorded that out of total $206 \mathrm{CL}$ biopsies, $49.5 \%$ biopsies were found to be positive for $L$. 
major, $28.6 \%$ biopsies were positive for $L$. tropica, 3.9\% were found to be positive for $L$.

infantum/donovani. In addition, all tested $\mathrm{CL}$ biopsies showed negative results for Leishmania mexicana (L. mexicana) and Leishmania viannia (L. viannia). Therefore, the aims of the current study were to use molecular tools to detect and identify the Leishmania species infecting humans and stray dogs in AlQassim province and Riyadh city, Saudi Arabia in order to better understand the epidemiology of the infection.

\section{Materials And Methods}

\section{Ethical approval}

This study was reviewed and approved by the Ethics Committee of the Department of Biological Science at Shaqra University, according to the ethical principles of animal research (protocol SH 2-2017).

\section{Study areas}

The investigation was conducted from January 2018 to May 2019 in Al-Qassim province and Riyadh city, Saudi Arabia. Al-Qassim province is located at the central part of Saudi Arabia (latitude $25^{\circ}-23^{\circ} \mathrm{N}$ and longitude $42^{\circ}-24^{\circ} \mathrm{E}$ ). It has an area of about $58.046 \mathrm{~km}^{2}$ with a population of $1,423.000$ people in 2017 [19]. Al-Qassim province is known as an agricultural region and it has a typical desert climate, with an average temperature of $13^{\circ} \mathrm{C}$ and hot summer (an average temperature of $35^{\circ} \mathrm{C}$ ), with few annual rainfalls $(214 \mathrm{~mm}$ ) and low humidity ranging from $25 \%$ to $76 \%$ (http://www.pme.gov.sa). Conversely, Riyadh city is the capital of Saudi Arabia (latitude $24^{\circ}-08^{\circ} \mathrm{N}$ and longitude $47^{\circ}-18^{\circ} \mathrm{E}$ ), with an area of about $1798 \mathrm{~km}^{2}$ and inhabited by approximately seven million people in 2017 [19]. Riyadh is characterized by very hot summers with an average temperature of $45^{\circ} \mathrm{C}$ in July, whereas winters are cold. The overall climate is arid, with scarce annual precipitations $(21.4 \mathrm{~mm})$, with a relative humidity ranging from $10 \%$ to $47 \%$ throughout the year. Riyadh is also known to have many dust storms (http://www.pme.gov.sa) (Figure 1).

\section{Patients Biopsy tissue collections and DNA extraction}

A total of 27 suspected patients were attended in both King Saud Medical City in Riyadh city $(n=16)$ and Buraydah Central Hospital $(n=11)$ in Al-Qassim province. All samples were diagnosed after clinical and microscopy examination [20]. Briefly, skin biopsies (i.e., 5-10 mm of diameter) were taken under sterile conditions from the border of the ulcer and cutaneous lesions and DNA samples were extracted from all biopsies by MagNaA pure DNA extraction Pure LC DNA Isolation Kit (Roche Applied Science, Mannheim, Germany) according to the manufacturer's instructions and the extracted DNA was quantified by Nanodrop spectrophotometer (Thermo, USA), DNA concentration differed from sample to another, but 
it ranged from $18 \mathrm{ng} / \mathrm{ul}$ to $33 \mathrm{ng} / \mathrm{ul}$, and an aliquot $\left(100 \mu\right.$ l of DNA from each sample) was stored at $-20{ }^{\circ} \mathrm{C}$ prior to nPCR amplification and analysis.

\section{Sampling of stray dogs}

From January 2018 to May 2019, 311 stray dogs were trapped in Al-Qassim province by bait traps (Havahart ${ }^{\circledR}$ ) (Figure 1).Dogs were examined physically for canine leishmaniasis skin lesions in the field. Seven dogs were suspected for canine leishmaniasis due to the presence of cutaneous nodules or ulcerated lesions on the skin (Table 1). Skin biopsies ( $5 \mathrm{~mm}$ in diameter) were taken under sterile conditions from the border of the ulcer and inoculated into medium M199 supplemented (Gibco, Life technologies, Germany) with $25 \mathrm{mmol} / \mathrm{L}$ HEPES (pH:7.5) and 20\% fetal bovine serum (Gibco, Life technologies, Germany) followed by incubation at $24{ }^{\circ} \mathrm{C}$. Ten days later parasites were harvested and washed with ice-cold phosphate buffered saline (PBS, $\mathrm{pH}$ : 7.4) and stored in $-20^{\circ} \mathrm{C}$ before DNA isolation. DNA from parasites cultures was isolated by using the ReliaPrep ${ }^{\mathrm{TM}}$ gDNA Tissue Miniprep System Kit (Promega, Madison, United States), following the manufacturer's instructions.

\section{Leishmania Nested PCR (nPCR)}

The specific external CSB2XF primers (5囚-ATTTTTCGCGATTTTCGCAGAAACG-3囚) and CSB1XR (5囚CGAGTAGCAGAAACTCCCGTTCA-3囚) were used initially. In the second step, specific internal $13 Z$ primers (5囚-ACTGGGGGTTGGTGTAAAATAG-3囚) and LiR (5囚-TCGCAGAACGCCCCT-3囚) were applied [21]. The specificity and sensitivity of this primers is reported to be $92 \%$ and $100 \%$, respectively [21]. In addition, these primers were able to track and multiply the variable part of all forms of the Leishmania kDNA. Amplified fragments of $L$. infantum were $680 \mathrm{bp}$ in length and fragments of $L$. tropica and $L$. major were 750 and 560 bp in length, respectively [21]. The first step of PCR master mix that included CSB2XF and CSB1XR were applied using AccuPower ${ }^{\circledR}$ PCR PreMix kit (Bioneer, Daejeon, Korea). The prepared PCR premix volumes contained $\mathrm{KCl} 30 \mathrm{mM}, \mathrm{MgCl}_{2} 1.5 \mathrm{mM}$, Tris-HCL (pH 9.0) $10 \mathrm{mM}$, Taq DNA polymerase, and dNTP were adjusted to $2 \mu \mathrm{l}$. In addition, $1 \mu \mathrm{l}$ of the first step of each initial CSB1XR and CSB2XF primers at concentrations of $10 \mathrm{pmol} / \mathrm{uL}$ (Bioneer, Daejeon, Korea) and $3 \mu \mathrm{l}$ of DNA were added to the complex. Finally, $13 \mu$ l of deionized water ( $(\mathrm{ddH} 20$ ) were added for a total volume of $20 \mu \mathrm{l}$ for reaction. The reaction was performed in a thermal cycler (Techne TC-3000, USA) by set up the following conditions; initial denaturation temperature of $94{ }^{\circ} \mathrm{C}$ for 5 min; followed by 30 cycles at denaturation $94{ }^{\circ} \mathrm{C}$ for $30 \mathrm{~s}$, annealing $55^{\circ} \mathrm{C}$ for $60 \mathrm{~s}$, extension $72{ }^{\circ} \mathrm{C}$ for $60 \mathrm{~s}$, final extension at $72{ }^{\circ} \mathrm{C}$ for $7 \mathrm{~min}$ and then the reaction was held at $4{ }^{\circ} \mathrm{C}$. The second step of PCR included $13 Z$ and LiR primers and the same PCR master mix except $3 \mu \mathrm{L}$ of template PCR product. After that, PCR products were electrophoresed on a $1.5 \%$ agarose gel containing $1 \mu \mathrm{L}$ Syber safe (Thermo Scientific ${ }^{\mathrm{TM}}$, Nalgene, UK) in Tris-acetate-EDTA buffer at $100 \mathrm{~V}$ for 45 min and visualized under UV imaging system (ImageQuant Laz4000, GE Healthcare Life Science, 
Hammersmith, UK). The size of each sample was estimated by comparison with a 100 bp DNA Ladder Marker (Solis BioDyne OU, Estonia).

\section{Leishmania kDNA sequencing and BLAST analysis}

Positive amplified products of Leishmania species were sent to Macrogen (South Korea) for sequencing, and the results were compared with the sequences available in GenBank database using BLAST (http://blast.ncbi.nlm. nih.gov/). The BLAST analysis was performed based on NCBI-BLAST alignment identification and an UPGMA tree performed based on distances calculated using a composite likelihood model (MEGA 7.0 version). Bootstrap values were determined with 1,000 replicates of the data sets [22].

\section{Results}

Of the 27 human patients examined, five from Riyadh and two from Al-Qassim were positive to $L$. major and $L$. tropica respectively (Figure 2 and 3 ). Of 311 dogs, seven (2.3\%) presented with thick cutaneous lesions (i.e., $1.5 \times 5$ centimeters) in different anatomical sites (e.g., nose, muzzle, abdomen and between fingers) and five of them were positive to $L$. tropica. Sequencing analysis of Leishmania kDNA confirmed that the five positive samples (nos. $\mathrm{H} 1-\mathrm{H} 5$ ) of the human patients from Riyadh were all L. major with a size ranging from $441 \mathrm{bp}$ to $451 \mathrm{bp}$ yielding a nucleotide identity ranging from $99.34 \%$ to $100 \%$ with query cover $100 \%$ with previous L. major sequences from Iraq (MN313423). Leishmania sequences from two human patients (no. $\mathrm{H} 1$ and $\mathrm{H} 3$ ) from Al-Qassim were most similar $99.66 \%$ to $100 \%$ with query cover $100 \%$, respectively to $L$. tropica from Iraq (MF166799) (Figure 4). Sequences of Leishmania kDNA from stray dogs (no. D5, D6 and D7) were closely related (i.e., $99.33 \%$ to $99.80 \%$ ) to kDNA of L. tropica from Iraq (MF166799), whereas two sequences (no. D2 and D4) displayed a close nucleotide identity (i.e., 99.35\% and 99,80) to L. tropica kDNA from Iraq (MN334665) and UK (AF308689), respectively (Figure 4). Phylogenetic tree clustered L. major (no. $\mathrm{H} 1-\mathrm{H} 5$ ) and L. tropica (no H1 and $\mathrm{H} 3$ ) sequences from human samples to those from Iraq (accession numbers MN313423 and MF166799, respectively), and the phylogenetic tree clustered L. tropica (no. D2 and D4) from Iraq and UK (accession numbers MN334665 and AF308689, respectively), while (no. D5, D6 and D7) sequences from dog's samples to those from Iraq isolate (accession number MF166799) Figure 4. In addition, the isolates of $L$. tropica from human and dogs in present study were closely related (i.e., $98.60 \%$ to $99.65 \%$ with query cover ranged $98.20 \%-99.50 \%$ ) to kDNA of L. tropica (Saudi strain, MHOM/SA/91/WR1063) that recorded on GenBank (accession number $\mathrm{X} 84845.1$ ).

\section{Discussion}

This study provides molecular evidence of the circulation of $L$. major and $L$. tropica in human and dog populations from the investigated areas. The above Leishmania spp. have already been recorded as 
agents of cutaneous leishmaniases in Saudi Arabia and Middle Eastern countries [23-26]. However, $L$. tropica infection has been herein molecularly diagnosed for the first time in humans and dogs in the central part of the Saudi Arabia since it was previously reported in the west and southern west of Saudi Arabia in association with the distribution of the sand fly species (i.e., Phlebotomus sergenti), which is a proper vector for that species [27]. Conversely, L. major is more prevalent throughout the Country and can be found in the open deserts regions of Saudi Arabia [2, 28]. Previous studies in Saudi Arabia have reported the natural infection of $L$. major in dogs using enzymatic biochemical methods [29, 30], though no clinical information was available, nor serology or molecular confirmation were performed. The high nucleotide identity of human L. major and L. tropica isolates with those of Iraq (accession number MN313423 and MF166799) as well as of dog L. tropica isolates with Iraq and UK (accession number MN334665, MF166799 and AF308689, respectively) was also confirmed by the phylogenetic dendrogram herein presented. Moreover, this study showed that the isolates of $L$. tropica from human and dogs were closely related to kDNA of L. tropica (Saudi strain, MHOM/SA/91/WR1063) that recorded on GenBank (accession number X84845.1). This might be due to the distribution of similar sand flies species in the different parts of Saudi Arabia and Middle East, which may act as proper vectors of both Leishmania spp. $[24,31]$. However, the phylogenetic analysis in this study was limited and performed based on the available sequences on GenBank based on the sequences of $L$. tropica and L. major in the Middle East countries particularly those from Iraq.

Of the 25 species of Phlebotomus reported in Saudi Arabia only five (i.e., Phlebotomus papatasi, Phlebotomus sergenti, Phlebotomus bergeroti, Phlebotomus kazeruni, and Phlebotomus arabicus) have been incriminated as vectors of $C L[27,28,32,33]$. Of these, $P$. papatasi is the main and most predominant vector species for $L$. major [28, 32], while $P$. sergenti is the natural vector species for $L$. tropica [27]. Presence of $P$. papatasiand $P$. sergenti in Al-Qassim province suggests that they could have a potential role in the transmission of human and canine leishmaniasis. Nonetheless, more studies are required to elucidate the role of Phlebotomus spp. in CL disease transmission in Saudi Arabia.

Stray dogs have been often diagnosed in Saudi Arabia, with clinical disease associated with Leishmania species, however previous studies focused on the epidemiology, clinical, histopathological and biochemical aspects $[11,29,30]$. Conversely, molecular studies have reported the occurrence of dog infection by Leishmania spp. in Qatar [34], L. tropica in Iran [26, 35] and Israel [36, 37] and by L. major in Iraq [23] and Israel [25], which are in agreement with the current study. Though CL is endemic in many parts of Saudi Arabia, the paucity of data concerning the relationship between the disease, the vectors and reservoirs is a major hindrance to understand the transmission cycles in endemic areas, considering that the distribution patterns can easly change through the years in specific geographic areas [38]. Data herein provided contribute to fill existing gaps in order to increase the alert by the Ministry of Health in Saudi Arabia in preventing outbreaks and the spread of CL.

\section{Conclusion}


This was the first study that detected and identified the causative agent of CL in stray dogs and patients from Saudi Arabia thus confirming that L. major and L. tropica are endemic in Al-Qassim province and Riyadh City. However, it is still unclear the relationship between the sand fly vectors and reservoirs and their specific role in the transmission cycles in endemic areas of Saudi Arabia. Further epidemiological and molecular studies focusing on CL these areas are advocated also in order to elaborate better strategic control plans and assess the risk for human health.

\section{Declarations}

\section{Ethics approval and consent to participate}

Blood and tissue sampling for this study was approved by the Ethical Research Committee, Shaqra University and complied with relevant guidelines for animal handling and welfare. (Approval no. SH 022017)

\section{Consent for publication}

Not applicable.

\section{Availability of data and material}

All data generated or analyzed during this study are included in this published article.

\section{Competing interests}

The authors declare that they have no competing interests.

\section{Funding}

Not applicable.

\section{Authors' contributions}

ADA , ASA and AAR conceived the study. MSA, ASA performed field works. ASA collected patient's and dog's samples. ASA, AAR and MAA carried out the biopsy tissue collections and DNA extraction. MAA, AAR and FAR performed laboratory works and analyzed data. ADA, MSA and FAR wrote the first draft of the manuscript. JM-R, DO, RD and ADA reviewed and wrote the final draft of the manuscript. All authors read and approved the final manuscript.

\section{Acknowledgements}

This work was kindly supported by Researcher Supporting Project (RSP2020/192) King Saud University. The authors would like to thank the staff of the Biological Sciences Department, Faculty of Science and Humanities, Shaqra University for kind technical support. 


\section{References}

1. WHO: Report on the Interregional meeting on leishmaniasis among neighbouring endemic countries in the Eastern Mediterranean, African and Europ, Amman,23-25 September 2018.

2. Abuzaid AA, Abdoon AM, Aldahan MA, Alzahrani AG, Alhakeem RF, Asiri AM, et al. Cutaneous Leishmaniasis in Saudi Arabia: A Comprehensive Overview. Vector Borne Zoonotic Dis. 2017, 17; 10:673-684.

3. Sirdar MK, Al-Zahrani MH, Dahlan AA, Sahli AA, Mohamed WS, Hejri YM, et al. Epidemiology and incidence of leishmaniasis in Jazan region, Saudi Arabia (2007-2015): An overview. J Entomol Zool Stud. 2018; 6: 859-864.

4. Hawash YA, Ismail KA, Abdel-Wahab MM, Khalifa M. Diagnosis, treatment and clinical features of cutaneous Leishmaniasis in Saudi Arabia. Korean J Parasitol.2018; 56 :229-236.

5. Al-Tawfiq JA, AbuKhamsin A: Cutaneous leishmaniasis: a 46-year study of the epidemiology and clinical features in Saudi Arabia (1956-2002). Int J Infect Dis. 2004; 8:244-250.

6. Amin TT, Al-Mohammed HI, Kaliyadan F, Mohammed BS: Cutaneous leishmaniasis in Al Hassa, Saudi Arabia: epidemiological trends from 2000 to 2010. Asian Pac J Trop Biomed. 2013; 6 :667672.

7. Alanazi AD, Alyousif MS, Saifi M, Alanazi IO. Epidemiological studies on cutaneous leishmaniasis in Ad-Dawadimi District, Saudi Arabia. Trop J Pharm Res. 2016 ; 15: 2709-2712.

8. Alanazi AD, Puschendorf R, Alyousif MS, Al-Khalifa MS, Alharbi S, et al. Molecular Detection of Leishmania spp. in Skin and Blood of Stray Dogs from Endemic Areas of Cutaneous Leishmaniasis in Saudi Arabia. Iran J Parasitol. 2019; 14(2):231-239.

9. Alanazi AD, Rahi AA, Ali AM, Alyousif MS, Alanazi IO, Mahmoud MS, et al. Molecular detection and phylogenetic analysis of Leishmania major in stray dogs in Riyadh Province, Saudi Arabia. Trop Biomed. 2019; 36(2):315-323.

10. Peters W, Elbihari S, Evans D. Leishmania infecting man and wild animals in Saudi Arabia. 2. Leishmania arabica n. sp. Trans R Soc Trop Med Hyg.1986; 80(4):497-502.

11. Elbihari S, Cheema A, El-Hassan A. Leishmania infecting man and wild animals in Saudi Arabia. 4. Canine cutaneous leishmaniasis in the Eastern Province. Trans R Soc Trop Med Hyg.1987; 81(6):925927.

12. Al-Zahrani M, Peters W, Evans D: Visceral leishmaniasis in man and dogs in south-west Saudi Arabia. Trans R Soc Trop Med Hyg. 1988; 82(6):857.

13. Akhavan AA, Mirhendi H, Khamesipour A, Alimohammadian MH, Rassi Y, Bet al. Leishmania species: detection and identification by nested PCR assay from skin samples of rodent reservoirs. Exp Parasitol. 2010;126(4):552-556.

14. Toz SO, Culha G, Zeyrek FY, Ertabaklar H, Alkan MZ, et al. A real-time ITS1-PCR based method in the diagnosis and species identification of Leishmania parasite from human and dog clinical samples in Turkey. PLoS Negl Trop Dis. 2013; 7(5):e2205. 
15. Silva RC, Richini-Pereira VB, Kikuti M, Marson PM, Langoni H. Detection of Leishmania (L.) infantum in stray dogs by molecular techniques with sensitive species-specific primers. Vet Q.2017; 37(1):2330.

16. Ferreira SA, Ituassu LT, Melo MN, Andrade AS. Evaluation of the conjunctival swab for canine visceral leishmaniasis diagnosis by PCR-hybridization in Minas Gerais State. Brazil Vet Parasitol. 152; 257263.

17. El-Beshbishy HA, Al-Ali KH, El-Badry AA. Molecular characterization of cutaneous leishmaniasis in AlMadinah Al-Munawarah province, western Saudi Arabia. Int J Infect Dis. 2013; 17(5):e334-e338.

18. Rasheed Z, Ahmed AA, Salem T, Al-Dhubaibi MS, Al Robaee AA,et al. Prevalence of Leishmania species among patients with cutaneous leishmaniasis in Qassim province of Saudi Arabia. BMC Public Health. 2019; 19(1):384.

19. General Authority for Statistic. Population Characteristics surveys, Saudi Arabia, pp. 25. https://www.stats.gov.sa/sites/default/files/population_characteristics_surveysar.pdf. 2017.

20. Akilov OE, Khachemoune A, Hasan T. Clinical manifestations and classification of Old World cutaneous leishmaniasis. Intl J Dermatol. 2007;46(2):132-142.

21. Noyes HA, Reyburn H, Bailey JW, Smith D. A nested-PCR-based schizodeme method for identifying Leishmania kinetoplast minicircle classes directly from clinical samples and its application to the study of the epidemiology of Leishmania tropica in Pakistan. JClin Microbiol 1998;36(10):28772881.

22. Kumar S, Stecher G, Tamura K. MEGA7: Molecular Evolutionary Genetics Analysis version 7.0 for bigger datasets. Mol Biol Evol. 2016; 33(7):1870-1874.

23. Al-Bajalan MM, Niranji SS, Al-Jaf SM, Kato H. First identification of L. majorin a dog in an endemic area of human cutaneous leishmaniasis in Iraq: molecular and phylogenetic studies. Parasitol Res. 2018;1-6.

24. Al-Salem WS, Pigott DM, Subramaniam K, Haines LR, Kelly-Hope L, et al. Cutaneous Leishmaniasis and Conflict in Syria. Emerg Infect Dis 2016; 22(5):931-933.

25. Baneth G, Nachum-Biala Y, Simon MS, Brenner O, Gaier S, et al. Leishmania major infection in a dog with cutaneous manifestations. Parasites \& Vectors. 2016; 9(1):246.

26. Bamorovat M, Sharifi I, Dabiri S, Mohammadi MA, Harandi MF, et al. Leishmania tropica in stray dogs in southeast Iran. Iran J Public Health. 2015, 44(10):1359-1366.

27. Al-Zahrani M, Peters W, Evans D, Chin C, Smith V, Lane R. Phlebotomus sergenti, a vector of Leishmania tropica in Saudi Arabia. Trans R Soc Trop Med Hyg. 1988;82(3):416.

28. Haouas N, Amer O, Alshammri FF, Al-Shammari S, Remadi L, et al. Cutaneous leishmaniasis in northwestern Saudi Arabia: identification of sand fly fauna and parasites. Parasit Vectors. 2017; 10(1):544.

29. Peters W, Elbihari S, Liu C, Le Blancq S, Evans D, et al. Leishmania infecting man and wild animals in Saudi Arabia 1. General survey. Trans R Soc Trop Med Hyg. 1985; 79(6):831-839. 
30. Elbihari S, Kawasmeh Z, Al Naiem A. Possible reservoir host (s) of zoonotic cutaneous leishmaniasis in Al-Hassa oasis, Saudi Arabia. Ann Trop Med Parasit. 1984; 78(5):543-545.

31. Du R, Hotez PJ, Al-Salem WS, Acosta-Serrano A. Old world cutaneous leishmaniasis and refugee crises in the Middle East and North Africa. Public Library of Science; 2016.

32. Mustafa M, Hussein S, Ibrahim E, Al-Seghayer S, Al Amri S, Gradoni L: Phlebotomus papatasi (Scopoli), vector of zoonotic cutaneous leishmaniasis in Riyadh province, Saudi Arabia. Trans R Soc Trop Med Hyg. 1994; 88(1):40.

33. El-Beshbishy HA, Al-Ali KH, El-Badry AA. Molecular characterization of Leishmania infection in sand flies from Al-madinah Al-munawarah province, western Saudi Arabia. Exp Parasitol. 2013; 134(2):211-215.

34. Lima C, Colella V, Latrofa MS, Cardoso L, Otranto D, Alho AM. Molecular detection of Leishmania spp. in dogs and a cat from Doha, Qatar. Parasit Vectors. 2019; 12(1):125.

35. Mohebali M, Malmasi A, Hajjaran H, Jamshidi S, Akhoundi B, Rezaei M, Janitabar S, Zarei H, Charehdar S: Disseminated leishmaniasis caused by Leishmania tropica in a puppy from Karaj, Central Iran. Iran J Parasitol. 2011; 6(2):69.

36. Baneth G, Zivotofsky D, Nachum-Biala Y, Yasur-Landau D, Botero A-M. Mucocutaneous Leishmania tropica infection in a dog from a human cutaneous leishmaniasis focus. Parasit Vectors. 2014; 7(1):118.

37. Baneth G, Yasur-Landau D, Gilad M, Nachum-Biala Y. Canine leishmaniosis caused by Leishmania major and Leishmania tropica: comparative findings and serology. Parasit Vectors. 2017; 10(1):113.

38. Mendoza-Roldan J, Benelli G, Panarese R, latta R, Furlanello T, Beugnet F, Zatelli A, Otranto D. Leishmania infantum and Dirofilaria immitis infections in Italy, 2009-2019: changing distribution patterns. Parasit Vectors. 2020;13(1):193.

\section{Table}

Table 1: Data of suspect dogs by canine leishmaniasis that trapped in Al-Qassim province.

\begin{tabular}{|c|c|c|c|c|}
\hline Dog ID & Site of trapped dogs & Gender & Age (years) & Location of cutaneous lesions \\
\hline Dog No.1 & Unayzah & Male & 2 & left ear \\
\hline Dog No.2 & Al-Bukkayriah & Male & 1 & nose \\
\hline Dog No.3 & Buraydah & Male & 4 & abdomen \\
\hline Dog No.4 & Al-Bukkayriah & Female & 2 & under mouth lips \\
\hline Dog No.5 & Buraydah & Male & 3 & muzzle \\
\hline Dog No.6 & Ar Rass & Female & 3 & nose \\
\hline Dog No.7 & Buraydah & Male & 2 & upper right leg \\
\hline
\end{tabular}

\section{Figures}




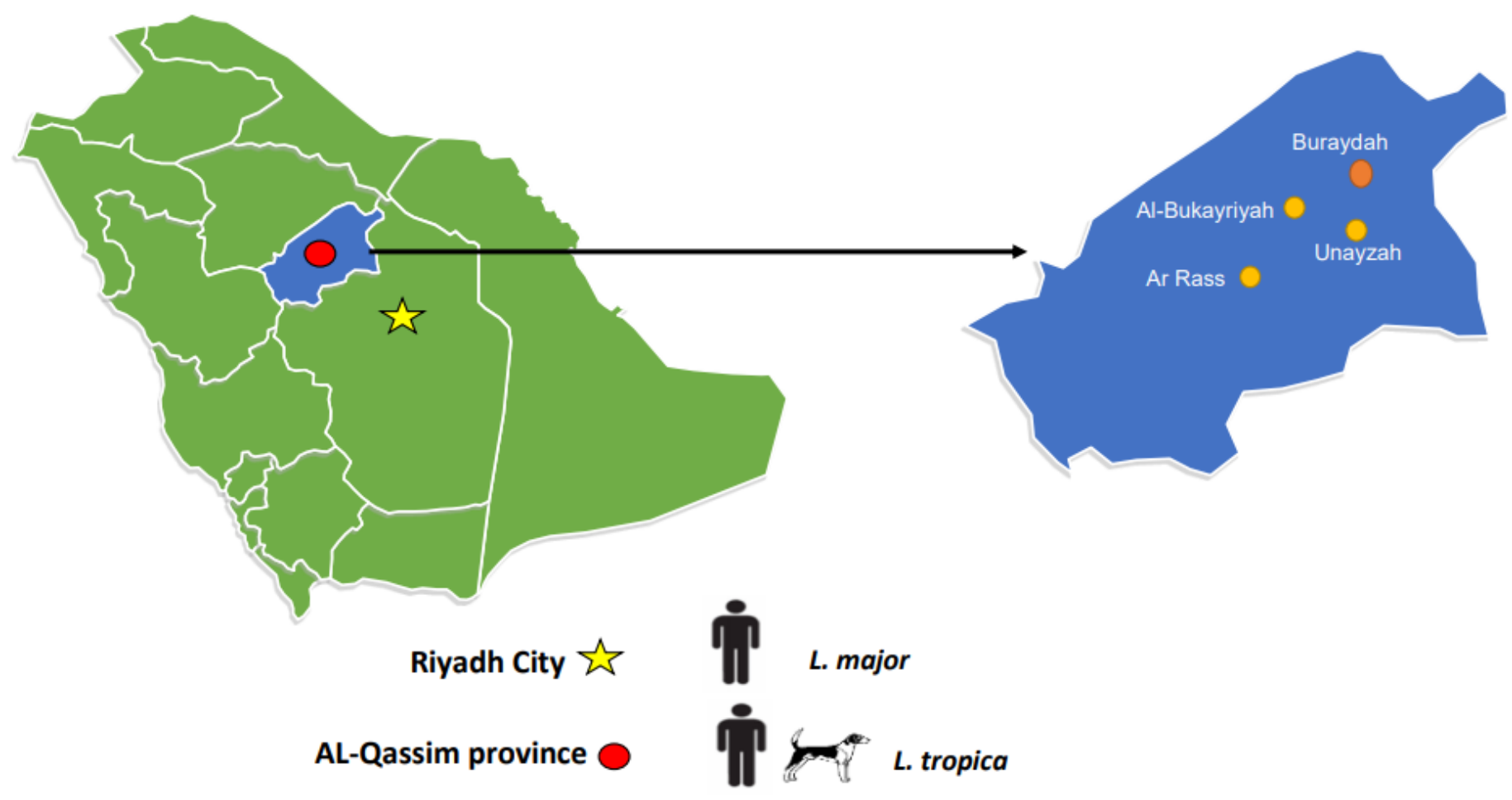

Figure 1

Map showing the location of the study areas in Saudi Arabia. 


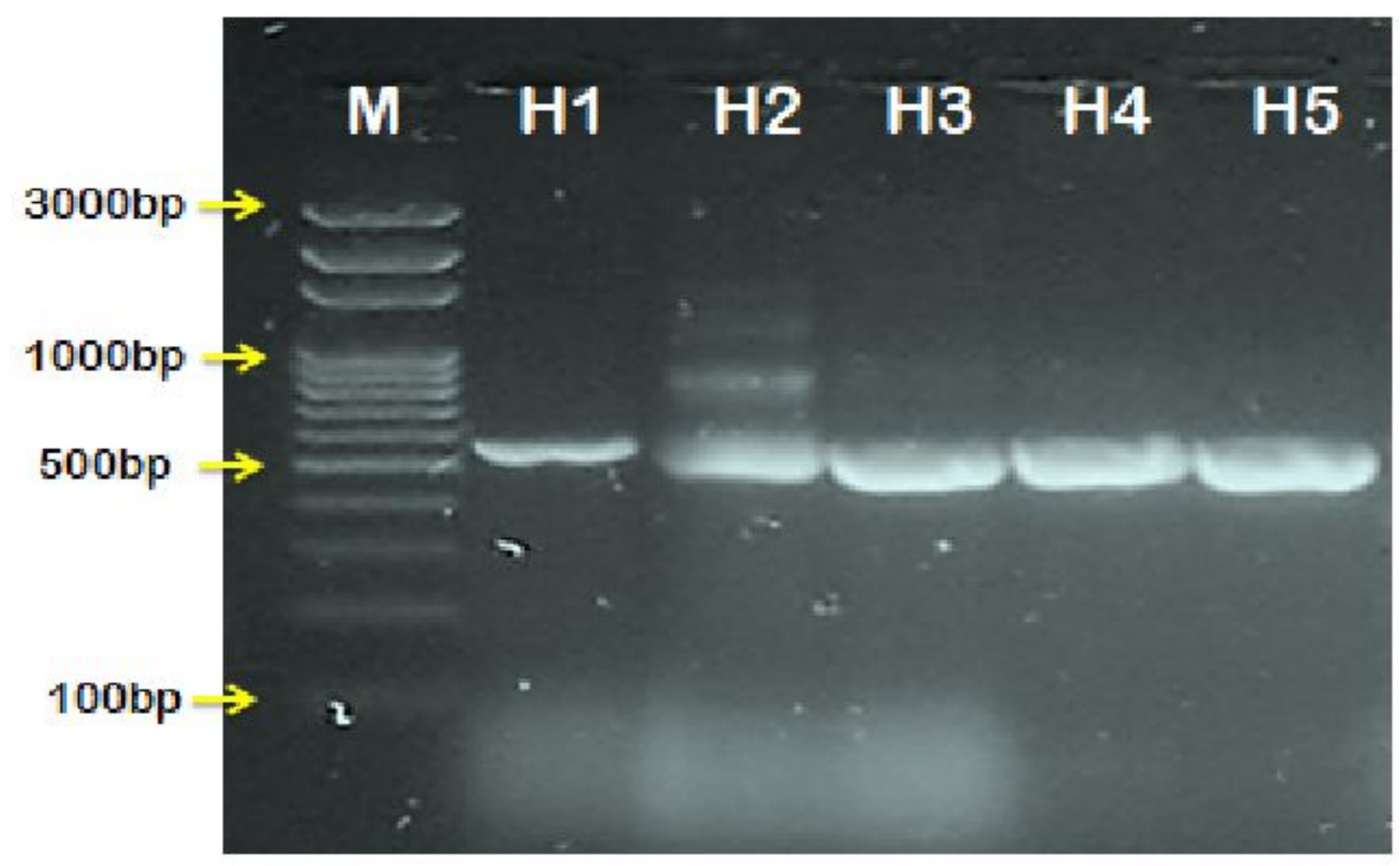

Figure 2

Agarose gel electrophoresis (1.7\%) image that show the Nested PCR product analysis of kDNA in Cutaneous L. major from human skin lesion samples from Riyadh city. Where M: marker (3000-100bp) and lane (H1 - H5) positive Human L. major at (560bp) nPCR product. 


\section{$\begin{array}{llllllllllll}M & \text { D1 D2 } & \text { D3 } & \text { D4 } & \text { D5 } & \text { D6 } & \text { D7 } & \text { H1 } & \text { H2 } & \text { H3 }\end{array}$}

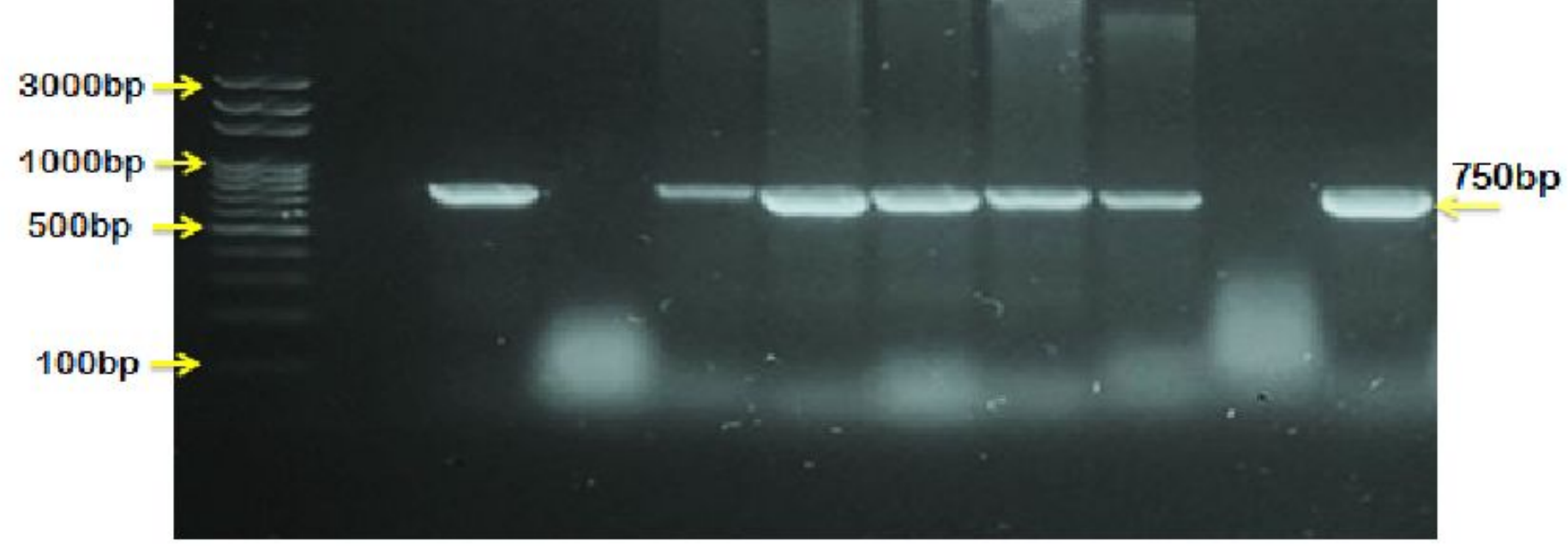

\section{Figure 3}

Agarose gel electrophoresis (1.7\%) image that show the Nested PCR product analysis of kDNA in Cutaneous L. tropica from dogs and human skin lesion samples from Al-Qassim province. Where M: marker (3000-100bp), lane (D2 and D4-D7) positive dogs L. tropica and lane (H1 and H3) positive Human L. tropica at (750bp) nPCR product. 


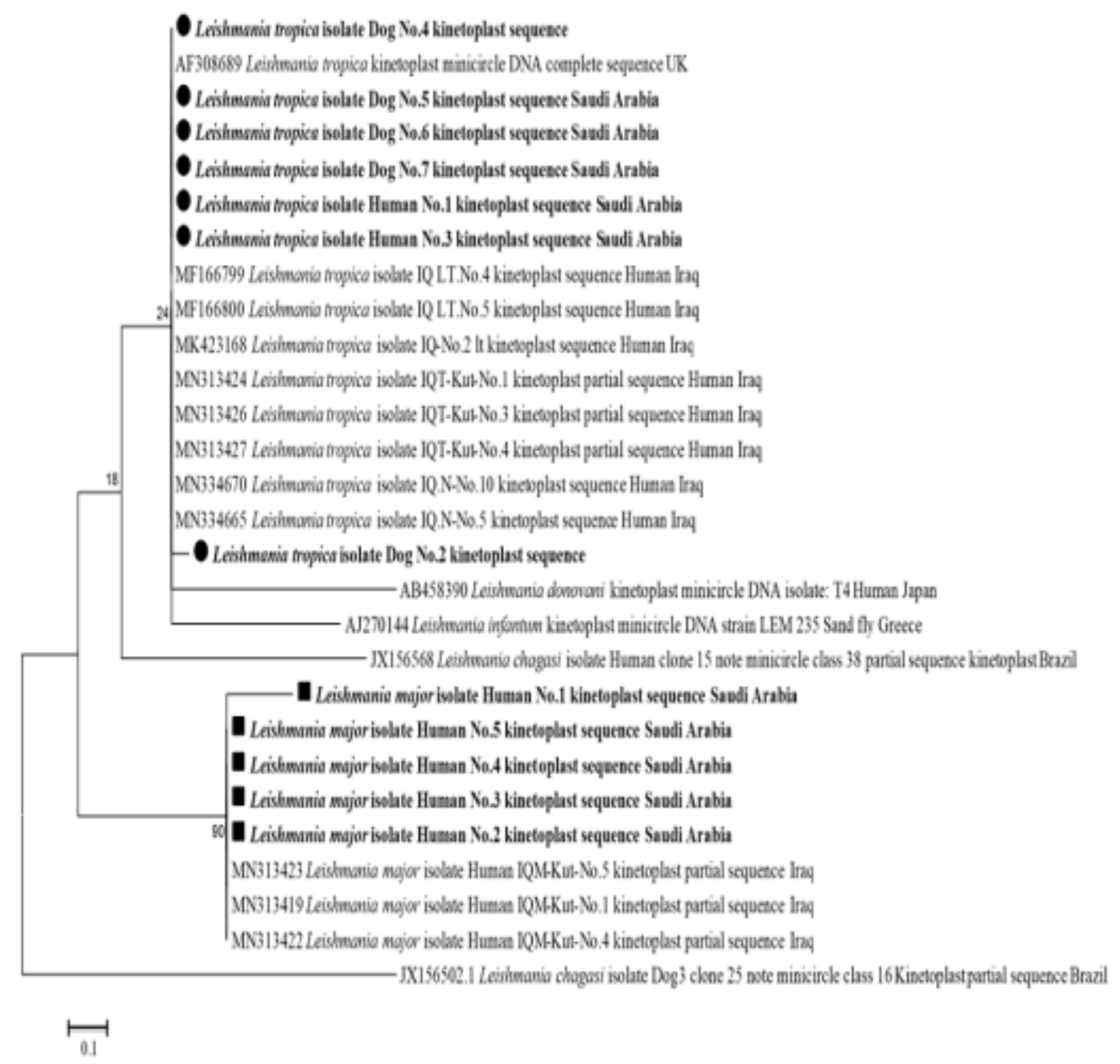

\section{Figure 4}

Phylogenetic tree analysis based on the partial sequence of kinetoplast DNA, non-protein coding region in local L.major and L. tropica human and dogs isolates that used for confirmative genetic detection and genetic relationship analysis. The evolutionary distances were computed using phylogenetic UPGMA tree type (MEGA 7.0 version).

\section{Supplementary Files}

This is a list of supplementary files associated with this preprint. Click to download.

- GraphicalAbstract.pdf 